\title{
Synthesis of DOT Use of Beam End Protection for Extending the Life of Bridges
}

\author{
Aleksandra Radlińska ${ }^{1), *}$, Leslie Myers McCarthy ${ }^{2)}$, James Matzke ${ }^{2)}$, and Francis Nagel $^{2)}$
}

(Received October 28, 2013, Accepted May 3, 2014)

\begin{abstract}
As the national transportation infrastructure ages and deteriorates, many existing bridges require frequent and costly maintenance and repairs. The objective of this work was to synthesize new and existing types of beam end coatings and treatments that have been proven to extend the life of new and existing concrete and steel bridge beams. A comprehensive literature review, along with online surveys and phone interviews of State department of transportations (DOTs) and coating manufacturers was conducted to gather information about existing and recently developed technologies. The study revealed that while many promising coatings and treatments are offered on the market, there is a lack of readily available laboratory results that would enable direct comparison of the available methods. This finding applies in terms of the coatings' durability and the potential for extending the service life of existing bridges. Most of the interviewed State DOTs' personnel assessed the products listed in respective DOT's Qualified Products Lists as performing 'well'. However, there was significant variability between states in the type of the products used. Among the agencies contacted, none was able to suggest the most promising or advanced products, either for concrete or steel bridge beam end treatments. This suggests that comprehensive laboratory evaluation would be necessary for selecting the best available beam end treatments and coatings.
\end{abstract}

Keywords: bridge beam ends treatments, structural deterioration, coatings.

\section{Introduction}

The condition of aging infrastructure in the United States has been an elevated concern for many years. The National Academy of Engineering included the restoration and improvement of urban infrastructure on the list of the top 14 Engineering Challenges facing society (Grand Challenges for Engineering 2012). The condition of the infrastructure could be significantly improved if restoration and repairs on the existing infrastructure components, and especially bridges, were implemented. A review of recent National Highway System (NHS) Bridge Deficiencies data that span over the recent decade (Table 1) reveals that approximately $8.2 \%$ of NHS bridges were classified as structurally deficient with the number consistently recorded to be above $8 \%$ over the recent decade (Status of the Nation's Highways, Bridges, and Transit: Conditions and Performance (2010)).

The cost of repairs of existing prestressed concrete I-beams has been reported to range from 35 to $69 \%$ of the

\footnotetext{
${ }^{1)}$ Department of Civil and Environmental Engineering, The Pennsylvania State University, University Park, PA 16802, USA.

*Corresponding Author; E-mail: ara@engr.psu.edu

${ }^{2)}$ Department of Civil and Environmental Engineering, Villanova University, Villanova, PA 19085, USA.

Copyright $($ The Author(s) 2014. This article is published with open access at Springerlink.com
}

cost of a superstructure replacement and is expected to extend the service life of a structure, along with replacing the deck joint (Needham and Douglas 2000). Bridge beam ends are specifically prone to corrosion and premature deterioration, typically due to bridge deck joint leakage (Ahlborn et al. 2002). As such, one way to enhance the current condition of bridges is to provide coatings or treatments to the existing and newly constructed bridge beams ends. The objective of this work was to evaluate existing methodologies and materials that have been proven to extend the life of new and existing concrete and steel bridge beams. The first part of the paper discusses protection systems of concrete bridge element, while the second part of the paper focuses on steel beam end treatments. Since majority of bridge beam constructed in the US are made out of concrete, more emphasis is placed on concrete protection systems.

\section{Literature Review of Products and Systems to Protect Concrete Bridge Elements}

Among the existing systems that extend the service life of concrete structures, coatings, sealers, overlays, electrochemical methods, corrosion inhibitors, admixtures, patching, reinforcing steel protection, membranes, and a combination of treatments can be mentioned. The ACI Concrete Repair Guide (ACI Committee 546 Concrete Repair Guide. ACI 546R-96 1996), for example, 
Table 1 Listing of NHS deficient bridges from 2001-2009 (Status of the Nation's Highways, Bridges, and Transit: Conditions and Performance 2010).

\begin{tabular}{|c|c|c|c|c|c|}
\hline \multirow[t]{2}{*}{ Analysis approach } & \multicolumn{5}{|c|}{ Percentage of deficient bridges by year } \\
\hline & 2001 & 2003 & 2005 & 2007 & 2009 \\
\hline \multicolumn{6}{|c|}{ Weighted by deck area } \\
\hline $\begin{array}{c}\text { Structurally deficient } \\
(\%)\end{array}$ & 8.4 & 8.8 & 8.5 & 8.4 & 8.2 \\
\hline $\begin{array}{c}\text { Functionally obsolete } \\
(\%)\end{array}$ & 22.0 & 20.9 & 21.3 & 21.3 & 21.0 \\
\hline Total deficient $(\%)$ & 30.4 & 29.7 & 29.8 & 29.7 & 29.2 \\
\hline \multicolumn{6}{|c|}{ Weighted by ave. daily traffic } \\
\hline $\begin{array}{c}\text { Structurally deficient } \\
(\%)\end{array}$ & 7.2 & 7.1 & 6.6 & 6.5 & 6.2 \\
\hline $\begin{array}{c}\text { Functionally obsolete } \\
(\%)\end{array}$ & 20.5 & 20.0 & 20.2 & 20.2 & 20.0 \\
\hline Total deficient $(\%)$ & 27.7 & 27.1 & 26.8 & 26.7 & 26.2 \\
\hline \multicolumn{6}{|c|}{ Weighted by bridge count } \\
\hline $\begin{array}{c}\text { Structurally deficient } \\
(\%)\end{array}$ & 6.0 & 5.9 & 5.7 & 5.5 & 5.2 \\
\hline $\begin{array}{c}\text { Functionally obsolete } \\
(\%)\end{array}$ & 17.4 & 17.0 & 16.9 & 16.7 & 16.6 \\
\hline Total deficient $(\%)$ & 23.3 & 22.9 & 22.6 & 22.2 & 21.9 \\
\hline
\end{tabular}

differentiates between topical treatment systems based the following application thickness ranges:

- Surface sealers are products of 10 mils $(0.25 \mathrm{~mm})$ or less in thickness that are applied to the surface of the concrete.

- High-build coatings consist of materials with a dry thickness greater than 10 mils $(0.25 \mathrm{~mm})$ and less than 30 mils $(0.75 \mathrm{~mm})$ and are applied to the surface of the concrete.

- Membranes are classified as surface treatments with a thickness greater than 30 mils $(0.7 \mathrm{~mm})$ and less than 250 mils $(6 \mathrm{~mm})$ and are applied to the surface of the concrete.

- Overlays are products of 250 mils $(6 \mathrm{~mm})$ or greater in thickness and are generally bonded to the surface of the concrete (Needham and Douglas 2000).

Following the Portland Cement Association's (PCA) classification (Kerkhoff 2007), four different types of topical protective treatments for concrete can be specified: (a) hydrophobic (water repelling); (b) sealers, which fill the pores at the surface and can be partly membrane-building; (c) membrane-building coatings; and, (d) mortar and concrete coatings.

Coatings are one or two component organic liquids that are applied to a prepared concrete surface in one or more coats. The primary purpose of the coating application is to prevent the ingress of water into the concrete and the diffusion of chloride ions. Different types of coatings include epoxies, acrylics, and urethanes. Epoxies are abrasion resistant and have a high adhesive strength, but are susceptible to degradation by UV light (Sohanghpurwala 2006). On the other hand, acrylics are brittle and normally have a low impact strength. Urethanes have a high impact strength and good weathering characteristics, but low abrasion resistance. The service life of coatings depends on the type of coating material applied and the field exposure conditions.

Sealers are solvent-based liquids that are applied to a prepared concrete surface to prevent the entry of liquid water and harmful ions (Holland 1992; Paul 1998), in order to mitigate corrosion, alkali-aggregate reaction, and other forms of deterioration. Sealers can be classified into penetrating sealers and surface sealers. Penetrating sealers react with the pore structure within hardened concrete to create a nonwettable surface, in order to prevent liquid water from entering the concrete. However, they are very permeable to water vapor (Cady 1994; Henry 2004; ACI 345.1R-06 Guide for Maintenance of Concrete Bridge Members 2006; AlGahtani et al. 1999; Silano 1993).

Overlays reduce moisture intrusion, improve durability, and provide corrosion resistance by delaying the intrusion of chlorides into the bridgedeck. They are also used to enhance appearance of the concrete surface and are very effective in masking cracks and existing repairs. Some overlays include low slump concrete formulations, polymer concrete, epoxies, certain methyl methacrylates, and polymer-modified concrete (Sohanghpurwala 2006). Overlays are not as effective in existing structures because if chloride ions are present, the only protection of the overlay is a decrease in moisture infiltration (Silano 1993). 
Membranes include urethanes, acrylics, epoxies, neoprenes, polymer concrete, certain methyl methacrylates, and bituminous products (ACI Committee 46 Concrete Repair Guide 1996). Waterproof membranes protect against deterioration induced by freeze-thaw cycles and provide a layer that slows down the ingression of chlorides that corrode reinforcement (Ahlborn et al. 2002). A relatively smooth surface is required for the application of liquid membranes.

Corrosion inhibitors slow down or prevent corrosion of reinforcing steel in concrete. They are meant to supplement the natural ability of the concrete to protect the embedded reinforcement by forming a passivating oxide layer on the steel. The most common inhibitor products contain calcium nitrate. Migrating corrosion inhibitors (MCIs) are also available and are designed to migrate to the embedded reinforcing to protect it against future corrosion (Sohanghpurwala 2006). Corrosion inhibitors are often used in conjunction with other corrosion protection systems, such as epoxy coated steel. They are generally used as admixtures in concrete for new construction, but can also be used for repairs by being admixed into concrete for patches, sprayed, or painted onto the surface of concrete beam ends.

Patching materials are used to replace localized areas of deteriorated concrete. They usually have a short service life, because typically they do not address the cause of the deterioration (corrosion of the reinforcing bars).

According to NCHRP Synthesis Report 398 (Sohanghpurwala 2009), cathodic protection is the only technology that can directly stop corrosion in reinforced concrete structures. They are typically reported to have high installation costs, but in contrast, also have lower life-cycle costs. The challenge reported is that higher levels of monitoring and maintenance for this type of protections are required. The extension of service life is dependent on the service life of the anode material and the maintenance of the system. The performance and durability of anode materials is crucial to the overall success of the system. Failures have been reported in cases of experimenting with new systems, when agencies installed systems without requisite experience and knowledge, when systems were not matched to the structure or the environment, for the systems that were improperly designed or incorrectly installed, and when systems were not monitored or maintained appropriately.

Finally, coatings on reinforcing bars can be either applied to reinforcing bars prior to installation in a new concrete structure or applied for the purpose of corrosion control in damaged concrete structures. Proper surface preparation is essential to achieving maximum adhesion, which is the primary factor governing the performance of any protective coating.

In a study sponsored by the Wisconsin Highway Research Program (Tabatabai et al. 2005), extensive experiments were conducted to compare the effectiveness of four different treatments on prestressed concrete beam ends. The following treatments were tested:

- Carbon fiber-reinforced polymer wrap: that consisted of the carbon fiber fabric, primer, putty, and resin. Two fabric/resin layers (resin-sheet-resin-sheet) were installed on the beam with fiber orientation in the two layers at $90^{\circ}$ with respect to each other.

- Polymer resin coating: Two coats of the resin component of the REPLARK 30 system (no fiber) were applied with a paint roller after application of the primer and putty.

- Epoxy coating: Two coats of MASTERSEAL GP Epoxy Sealer (could be applied with a squeegee, roller, or spray equipment to a clean, dry surface).

- Sealer: Two coats of MASTERSEAL SL 40 VOC (solvent based silane penetrating sealer) applied using a roller and paint brush.

A salt-water distribution system was constructed to subject the beams to controlled salt-water exposure $(6 \% \mathrm{NaCl}$ solution) and to wet/dry cycles, consisting of 4 days of exposure to salt water followed by 3 days of drying. The sixmonth exposure did not result in concrete spalling or significant tendon corrosion, so it was necessary to accelerate corrosion in the specimens. This was achieved by applying a constant external voltage to the steel cage while maintaining the cyclic wetting and drying by subjecting the specimens to cyclic wetting and drying using a $6 \%$ sodium chloride solution and after exposure to the cyclic wetting and drying, the effectiveness of each treatment was evaluated based on the chloride content (measured as percent by weight of concrete), extent of cracking, and extent of observed strand corrosion. The fiber reinforced polymer (FRP) coating and polymer resin were found to be the most effective, followed by the epoxy coating, and then silane treatments. It was recommended that polymer resin or epoxy coating be used to protect prestressed concrete beam ends. It was reported that FRP wraps did not significantly improve performance over polymer resin coating and would only add to the cost.

It is important to note, that the work reported in (Tabatabai et al. 2005) focused on only four different products that have been updated and modified since the time of study. As such, the results of this report may not be representative of the general performance of sealers, epoxy, and polymer resin coatings.

Concrete surface treatment materials (silanes and siloxanes) were also investigated in a study by Ibrahim et al. (1999), as a means of delaying concrete deterioration due to sulfate attack, carbonation, and chloride-induced reinforcement corrosion. The following sealers and coatings were investigated: sodium silicate; silicon resin solution; silane/siloxane; silane/siloxane with an acrylic topcoat; alkyl-alkoxy silane; and a two-component acrylic coating. Silane/siloxane with an acrylic topcoat and a two-component acrylic coating were reported to be most effective in preventing the carbonation of concrete. Silane and silane/siloxane with a topcoat were effective in reducing chloride-induced reinforcement corrosion of in-service structures. Silane/siloxane with an acrylic topcoat was the most effective in minimizing the damage due to sulfate attack. On the other hand, silane/siloxane with acrylic topcoat and acrylic coating were effective in reducing ingress of $\mathrm{CO}_{2}$. The study ranked the treatments investigated in the following order (from best performance to worst performance): silane/ 
siloxane with an acrylic topcoat; silane, silane/siloxane; silicon resin solution; and, sodium silicate (Ibrahim et al. 1999).

The Kentucky Transportation Cabinet (KTC) is one of the few states that have an active program evaluating protective concrete coatings. In one of KTC projects, Younce et al. (2008) evaluated a protective coating that was applied to a concrete median barrier on a section of I- 65 in Louisville. This experimental project was the first trial of concrete coatings identified under KYSPR 05-271 'Coatings, Sealants and Fillers to Address Bridge Concrete Deterioration and Aesthetics-Phase 1'. The coatings systems identified under the study were intended to provide improved protection and aesthetics for reinforced concrete. This project proved that one candidate coatings system could be applied successfully on existing concrete (Younce et al. 2008; Palle and Hopwood 2006) but concluded that additional experimental work is necessary to adequately identify the best performing products.

A Michigan Department of Transportation report by Ahlborn et al. (R-1380) presented an excellent review of the causes and remediations for prestressed concrete I-beam end deterioration, including the development of inspection procedures for prestressed concrete I-beams, identification of preventive maintenance strategies to extend the service life of prestressed concrete I-beams ends, and evaluating the repair techniques. The forms of distress most frequently observed included concrete spalling, delamination, cracking, and corrosion of reinforcement. The MDOT study did not analyze specific coatings that extend the life of existing or new beams; rather, it listed a wide range of available products, as recommended by PCA (Portland Cement Association (PCA) Concrete Information 2001) and cited some existing data on general performance of two-part epoxies, siloxanes, silanes, and multi-component treatments (silane, siloxanes, methyl methacrylate) (Whiting et al. 1993; Whiting et al. 1998; Whiting et al. 1992). The study suggested the choice of repair as based on the existing condition of the beam end, as shown in Table 2. Sealers and coatings are generally recommended for beam ends with low distress levels, but noted that the MDOT report did not contain any experimental component.

\section{Information on Beam End Treatments Obtained from Surveys and Interviews}

Three electronic surveys were created to obtain detailed information regarding the treatment of beam ends. Two surveys were sent directly to treatment manufacturers (one survey to concrete and one survey to steel coatings producers) and one was sent to state department of transportation (DOTs) representatives and other organizations or agencies.

The electronic surveys were active for a period of 8 weeks during the months of July and August 2011. A total of 190 surveys were sent, including 127 surveys sent to DOT and other agencies, 46 surveys sent to concrete coatings manufacturers, and 17 surveys sent to steel treatment manufacturers. The survey response rates were $26 \%$ for agencies, $35 \%$ for concrete coatings manufacturers, and $35 \%$ for steel coatings manufacturers, respectively. Figure 1 shows the map of the states that replied to the survey.

\subsection{Survey Results for Concrete Coatings and Treatments}

A summary of all the responses related to concrete beam end coatings and treatments are presented in Fig. 2. Among the products recommended for concrete coatings, the majority contains an epoxy resin system. Some of the epoxy systems included an additional polyurethane resin component, while other products that were recommended include silanes and silicones.

The majority of DOTs replied that they do not coat the ends of concrete beams. Among all the respondents, $77 \%$ indicated that their state either does not coat (or rarely coats) the beam ends. The Nebraska Department of Roads (NDOR) shared that with new concrete structures, the outside fascia of exterior girders is sealed with a siloxane or an acrylic sealer, but there is no special treatment of girder ends. The agencies that do use coating systems and provided product descriptions were Florida DOT, Illinois DOT, and Iowa DOT. Protective coatings, concrete sealers, latex acrylic primer, and an epoxy sealer were products reported by these DOTs. These systems all require frequent or periodic inspection and are estimated to last up to 10 years. It is interesting to note that a previous survey performed in 2001 (Ahlborn et al. 2002) also revealed that most states do not repair prestressed I-beams for end deterioration, and if they were to perform one, the state DOT specification would be used in the rehabilitation process.

In the concrete manufacturers survey, the manufacturers were solicited to provide product names, descriptions, and the type of coating technique recommended for use to protect concrete bridge beam ends. A summary of the results for the specific type of coatings identified can be seen in Table 3. Some of the products can be classified as more than one type of coating and therefore are counted more than once. Coatings and membranes were reported as the most

Table 2 Preventive maintenance and repair options for deteriorated beam ends (Status of the Nation's Highways, Bridges, and Transit: Conditions and Performance 2010).

\begin{tabular}{c|c|c}
\hline Low severity distress & Moderate severity distress & High severity distress \\
\hline \hline Sealers & Partial depth repair & Partial depth repair \\
\hline Coatings & Cathodic protection & - \\
\hline Do nothing & Combined sealers and coatings & Rent \\
\hline
\end{tabular}




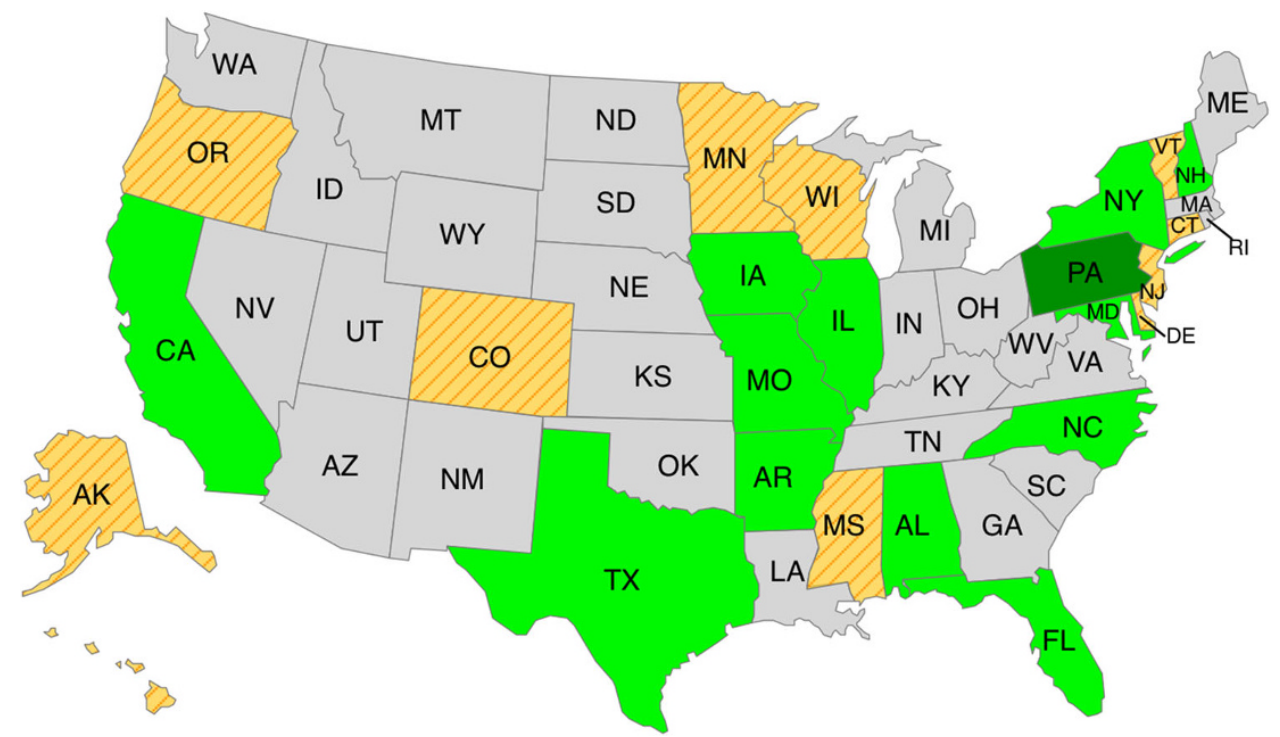

Fig. 1 Map of DOT survey response type (green states that replied, orange states that provided partial response, grey no response received, including $\mathrm{HI}$; darker green for $\mathrm{PA}$ indicates the state where research originated). (Color figure online).

\section{Concrete Coatings Survey Responses}

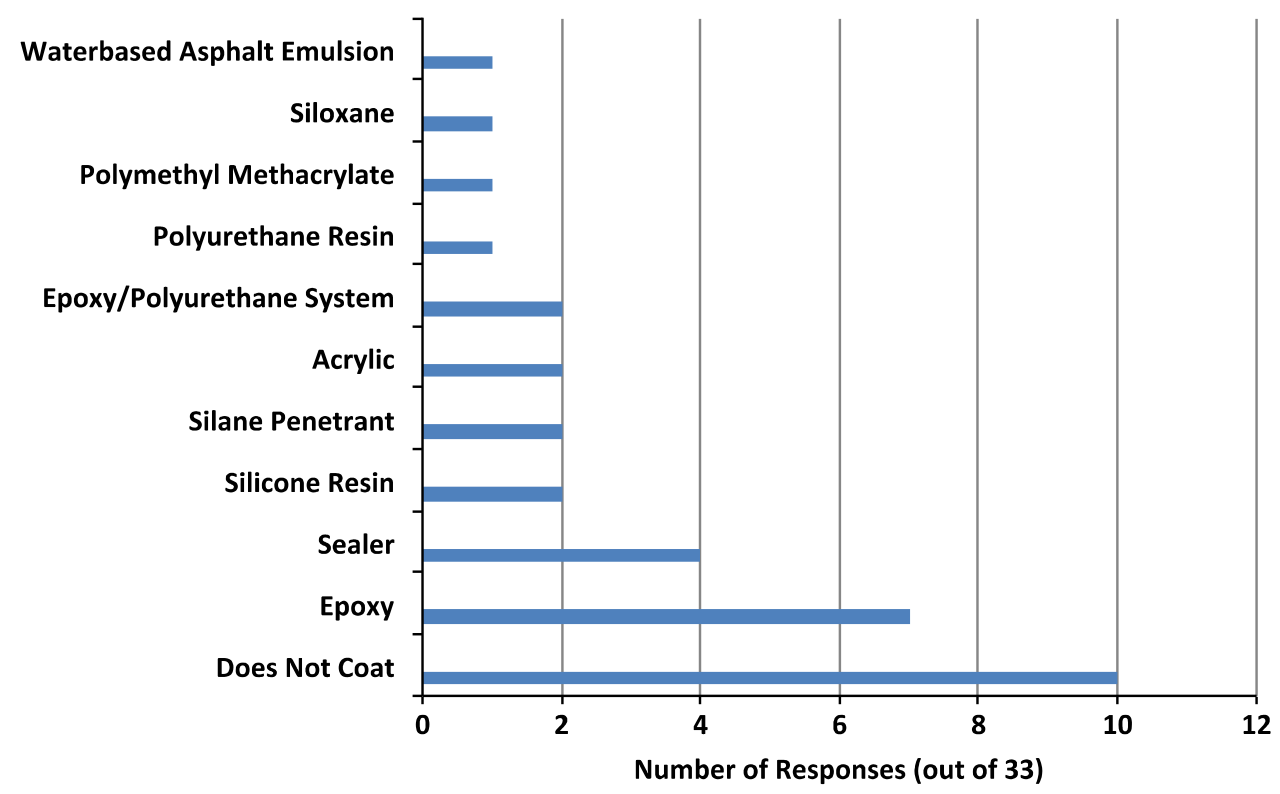

Fig. 2 Information about concrete coating systems provided by coatings manufacturers and agencies.

frequently used treatments, followed by sealers and combination systems.

The service life data of the coating systems obtained in the survey is compiled in Table 4 . It can be seen that $84 \%$ of respondents reported a service life for their products of 11-20 years. One of the more notable responses was the service life reported as 41-50 years for a penetrating sealer with water repellent silicates. This specific product is a deep penetrating sealer called Evercrete Deep Penetrating Sealer (DPS), reported by the manufacturer Evercrete Corporation. The product penetrates below the surface and chemically reacts with alkali and lime in the concrete, sealing against the ingress of moisture while allowing the concrete to breathe.

\subsection{Ranking of Concrete Products Based on Concrete Manufacturer Data}

While data available on steel coatings was reported to be consistent, data obtained from the concrete manufacturers was more complex. Therefore, multiple phone interviews were conducted to obtain additional information about available concrete beam end treatments. Based on all the 
Table 3 Types of coating products reported by concrete manufacturers survey.

\begin{tabular}{|c|c|c|c|}
\hline Type of coating & Number of products reported & Product names or description & Manufacturers \\
\hline \multirow[t]{8}{*}{ Coatings } & \multirow[t]{8}{*}{8} & TEXCOTE XL 70 BRIDGE COTE & Textured Coatings of America, Inc. \\
\hline & & $\begin{array}{c}\text { TEXCOTE XL } 70 \text { BRIDGECOTE } \\
\text { W/SILANE }\end{array}$ & Textured Coatings of America, Inc. \\
\hline & & $\begin{array}{c}\text { Multi laminate epoxy/urethane } \\
\text { coating system pecoraDeck } \\
\text { P-808 primer Pecoradeck P-806 } \\
\text { Top Coat }\end{array}$ & Pecora Corporation \\
\hline & & $\begin{array}{c}\text { Safe-Cure \& } \text { Seal EPX Duraguard } \\
\text { 310CRU }\end{array}$ & ChemMasters \\
\hline & & Epoxykote 100WB & ChemMasters \\
\hline & & Waterbased Epoxy & Pruett-Schaffer Chemical Co. \\
\hline & & $\begin{array}{c}\text { FX-498 Hydro Ester High Build } \\
\text { Coating }\end{array}$ & Fox Industries Inc. \\
\hline & & Epoxy: Plymastic 650 & Sherwin-Williams \\
\hline \multirow[t]{6}{*}{ Membranes } & \multirow[t]{6}{*}{6} & $\begin{array}{c}\text { Soprema Alsan RS (PMMA } \\
\text { waterproofing system) }\end{array}$ & Soprema Inc. \\
\hline & & $\begin{array}{c}\text { Soprema Alsan Flashing (Asphalt- } \\
\text { modified urethane) }\end{array}$ & Soprema Inc. \\
\hline & & $\begin{array}{c}\text { Multi laminate epoxy/urethane } \\
\text { coating system pecoraDeck } \\
\text { P-808 primer Pecoradeck P-806 } \\
\text { Top Coat }\end{array}$ & Pecora Corporation \\
\hline & & $\begin{array}{c}\text { Safe-Cure \& } \text { Seal EPX Duraguard } \\
\text { 310CRU }\end{array}$ & ChemMasters \\
\hline & & Epoxykote $100 \mathrm{WB}$ & ChemMasters \\
\hline & & Waterbased Asphalt Emulsion & Pruett-Schaffer Chemical Co. \\
\hline \multirow[t]{4}{*}{ Penetrating sealers } & \multirow[t]{4}{*}{4} & $\begin{array}{c}\text { Evercrete Deep Penetrating Sealer } \\
\text { (DPS) }\end{array}$ & Evercrete Corp. \\
\hline & & $\begin{array}{c}\text { TEXCOTE XL } 70 \text { BRIDGECOTE } \\
\text { W/SILANE }\end{array}$ & Textured Coatings of America, Inc. \\
\hline & & Sil-Act ATS-100LV & $\begin{array}{l}\text { Advanced Chemical Technologies } \\
\text { Inc. }\end{array}$ \\
\hline & & $\begin{array}{c}\text { Penetrating Concrete Sealer: SW } \\
\text { DOT Concrete Sealer } 100\end{array}$ & Sherwin-Williams \\
\hline \multirow[t]{4}{*}{ Surface sealers } & \multirow[t]{4}{*}{4} & $\begin{array}{c}\text { Dynapoxy Low Mod Epoxy - Low } \\
\text { Mod } 2 \text { component fast curing } \\
\text { epoxy based coating }\end{array}$ & Pecora Corporation \\
\hline & & $\begin{array}{c}\text { Safe-Cure \& } \text { Seal EPX Duraguard } \\
\text { 310CRU }\end{array}$ & ChemMasters \\
\hline & & Epoxykote 100WB & ChemMasters \\
\hline & & Sil-Act EP 700D & $\begin{array}{c}\text { Advanced Chemical Technologies } \\
\text { Inc. }\end{array}$ \\
\hline \multirow[t]{3}{*}{ Combination systems } & \multirow[t]{3}{*}{3} & Evercrete Top Seal (TS) & Evercrete Corp. \\
\hline & & $\begin{array}{c}\text { Si-Rex03 Silicone Resin Emulsion } \\
\text { Paint (SREP) }\end{array}$ & $\begin{array}{c}\text { Klaas Coatings (North America) } \\
\text { LLC }\end{array}$ \\
\hline & & $\begin{array}{c}\text { FX-460 Breathable Masonry } \\
\text { Coating System (1 Coat Primer, } 1 \\
\text { Coat Top Coat) }\end{array}$ & Fox Industries Inc. \\
\hline
\end{tabular}


Table 3 continued

\begin{tabular}{c|c|c|c}
\hline Type of coating & Number of products reported & Product names or description & Manufacturers \\
\hline Electochemical methods & 0 & & \\
\hline Corrosion inhibitors & 0 & & \\
\hline Admixtures & 0 & & \\
\hline Patching & 0 & & \\
\hline Reinforcing steel protection & 0 & & \\
\hline Overlays & 0 & & \\
\hline
\end{tabular}

data collected, a dynamic Excel spreadsheet was developed to rank the products based on key characteristics listed in the survey. These characteristics included a history of DOT use, time to first application, service life, cost, curing time, and durability aspects. The responses were ranked by assigning the highest score for the best performance. The maximum rating for different categories varied between 3 and 5 and the categories were assigned weighted importance that could be selected by the user. An example of a ranking that puts the most emphasis on time to first application, frequency of inspections, cost, service life, and curing time has been shown in Table 5. It should be mentioned here that the criteria selected here are for example purposes and the ranking and importance can be adjusted per user's data and preference.

Based on the criteria assumed in the case scenario presented in Table 5, the Evercrete Deep Penetrating Sealer, Waterbased Asphalt Emulsion, Texcote X1 70 Bridge Cote, and Texcote Xl 70 Bridge Cote with Silane were assessed based on the total score listed in the last column as the best products that have the potential to extend the life of concrete bridge beam ends. While the table presents a useful tool to compare effectiveness of existing products, presented ranking was developed solely based on the input provided by manufacturers and is not all-inclusive. A comprehensive laboratory evaluation of concrete coatings would be needed to provide basic materials comparison and evaluate their performance under accelerated aging condition. In addition to the top products from the ranking, the expanded study should also include Sikagard-62 mentioned by Iowa DOT, as well as products offered by BASF and Euclid company that were the most widely cited in the DOT qualified product lists (QPLs).

\section{Products and Systems to Protect Steel Bridge Elements}

There are many different combinations of primers, intermediate coats, and topcoats that can be applied to steel beam ends to protect the infrastructure components from corrosion. Most of the commonly-used steel systems employ all three aforementioned layers. Another system that exists to prevent corrosion is using hot-dipped galvanized steel, which may be coated or can be left uncoated; however, this process can be conducted in a controlled environment only (Helsel and Wissmar 2008). Frequently mentioned coatings for steel beam treatments include: polysiloxane systems which comprise of a zinc based primer and an epoxy siloxane top-coat, and inorganic zinc primer with an epoxy intermediate coat and a urethane top-coating.

One advantage of the organic zinc-rich coatings over the inorganic zinc-rich coatings was reported to be a definable cure period based on external temperature and humidity conditions, which allows application of a top layer with confidence that the primer has fully cured (Williams 2012). This makes organic zinc-rich primers easier to apply in the field where the temperature and humidity cannot be regulated. Other coating systems based on a zinc-rich primer use a polyaspartic polyurethane, polyurethane, or polysiloxane topcoat. There are other coating types, namely moisturecured urethanes, acrylic latexes, and epoxy resins, which may also be zinc-rich.

A Missouri Department of Transportation report (Myers et al. 2010) on structural steel coatings for corrosion mitigation mentions that drainage of water from the deck onto the superstructure was the primary factor leading to service failures of the coating. It was reported that inorganic zinc primers were effective at hindering corrosion; however, organic zinc primer had higher adhesive strengths. The document also reported that overcoating provides an alternative maintenance option that reduces cost and disruption of the highway system; however, it comes with an increased level of risk of early failure of the newly applied system (as opposed to the full blast and repaint approach). Additionally, polyurea type coatings were reported to be effective at producing bond strength, but the salt-induced corrosion inhibition was not as strong as the systems with a high solid zinc primer. Organic zinc primer was reported to be more effective due to higher adhesive strengths and a lower probability of the primer peeling off. A promising review of the application of micaceous iron oxide zinc primer with aliphatic polyurea polyaspartic topcoat system was reported to have almost equal performance in terms of salt-fog resistance when compared to blast cleaning and application of a zinc rich primer. It also provided the added feature of superior UV resistance with good freeze-thaw stability. 
Table 4 Expected service life of coatings reported by concrete manufacturers.

\begin{tabular}{|c|c|c|c|c|c|c|c|c|}
\hline \multirow[t]{2}{*}{ Type of Coating } & \multicolumn{8}{|c|}{ Expected Service Life (years) } \\
\hline & $0-5$ & $6-10$ & $11-15$ & $16-20$ & $21-30$ & $31-40$ & $41-50$ & $50+$ \\
\hline \multirow[t]{3}{*}{ Penetrating Sealers } & \multirow[t]{3}{*}{0} & 2 products: & 1 product: & \multirow[t]{3}{*}{0} & \multirow[t]{3}{*}{0} & \multirow[t]{3}{*}{0} & 1 product: & \multirow[t]{3}{*}{0} \\
\hline & & $\begin{array}{c}\text { - Sil-Act ATS- } \\
\text { 100LV }\end{array}$ & \multirow{2}{*}{$\begin{array}{c}\text { - TEXCOTE XL } \\
70 \\
\text { BRIDGECOTE } \\
\text { W/SILANE }\end{array}$} & & & & \multirow[t]{2}{*}{$\begin{array}{c}\text { - Evercrete Deep } \\
\text { Penetrating } \\
\text { Sealer (DPS) }\end{array}$} & \\
\hline & & $\begin{array}{c}- \text { SW DOT } \\
\text { Concrete Sealer } \\
100\end{array}$ & & & & & & \\
\hline \multirow[t]{3}{*}{ Surface Sealer } & \multirow[t]{3}{*}{0} & \multirow[t]{3}{*}{0} & 2 products: & 2 products: & \multirow[t]{3}{*}{0} & \multirow[t]{3}{*}{0} & \multirow[t]{3}{*}{0} & \multirow[t]{3}{*}{0} \\
\hline & & & $\begin{array}{c}\text { - Epoxykote } \\
100 \mathrm{WB}\end{array}$ & - Sil-Act EP 700D & & & & \\
\hline & & & $\begin{array}{c}\text { - Dynapoxy Low } \\
\text { Mod Epoxy }\end{array}$ & $\begin{array}{c}- \text { Safe-Cure \& Seal } \\
\text { EPX Duraguard } \\
\text { 310CRU }\end{array}$ & & & & \\
\hline \multirow[t]{5}{*}{ Membranes } & \multirow[t]{5}{*}{0} & \multirow[t]{5}{*}{0} & 2 products: & 4 products: & \multirow[t]{5}{*}{0} & \multirow[t]{5}{*}{0} & \multirow[t]{5}{*}{0} & \multirow[t]{5}{*}{0} \\
\hline & & & \multirow{2}{*}{$\begin{array}{c}\text { - PecoraDeck } \\
\text { P-808 primer } \\
\text { Pecoradeck } \\
\text { P-806 Top Coat }\end{array}$} & $\begin{array}{c}\text { - Soprema Alsan } \\
\text { RS }\end{array}$ & & & & \\
\hline & & & & \begin{tabular}{|c|} 
- Soprema Alsan \\
Flashing
\end{tabular} & & & & \\
\hline & & & \multirow[t]{2}{*}{$\begin{array}{c}\text { - Epoxykote } \\
100 \mathrm{WB}\end{array}$} & $\begin{array}{c}- \text { Safe-Cure \& Seal } \\
\text { EPX Duraguard } \\
\text { 310CRU }\end{array}$ & & & & \\
\hline & & & & $\begin{array}{l}\text { - Waterbased } \\
\text { Asphalt Emulsion }\end{array}$ & & & & \\
\hline \multirow[t]{7}{*}{ Coatings } & \multirow[t]{7}{*}{0} & \multirow[t]{7}{*}{0} & 5 products: & 3 products: & \multirow[t]{7}{*}{0} & \multirow[t]{7}{*}{0} & \multirow[t]{7}{*}{0} & \multirow[t]{7}{*}{0} \\
\hline & & & $\begin{array}{c}\text { - FX-498 HYDRO } \\
\text { ESTER HIGH }\end{array}$ & $\begin{array}{c}- \text { Epoxy Plymastic } \\
650\end{array}$ & & & & \\
\hline & & & COATING & $\begin{array}{c}\text { - Waterbased } \\
\text { Epoxy }\end{array}$ & & & & \\
\hline & & & $\begin{array}{c}\text { - Epoxykote } \\
100 \mathrm{WB}\end{array}$ & $\begin{array}{r}- \text { Safe-Cure \& Seal } \\
\text { EPX Duraguard }\end{array}$ & & & & \\
\hline & & & $\begin{array}{l}\text { PecoraDeck } \\
\text { P-808 primer } \\
\text { Pecoradeck } \\
\text { P-806 Top Coat }\end{array}$ & ग10СКО & & & & \\
\hline & & & $\begin{array}{c}- \text { TEXCOTE XL } \\
70 \text { BRIDGE } \\
\text { COTE }\end{array}$ & & & & & \\
\hline & & & \begin{tabular}{|c|} 
TEXCOTE XL \\
70 \\
BRIDGECOTE \\
W/SILANE
\end{tabular} & & & & & \\
\hline Combination & 1 product: & 0 & 0 & 2 products: & 0 & 0 & 0 & 0 \\
\hline & & & & $\begin{array}{c}- \text { Si-Rex03 Silicone } \\
\text { Resin Emulsion } \\
\text { Paint (SREP) }\end{array}$ & & & & \\
\hline & $\begin{array}{c}\text { - Evercrete Top } \\
\text { Seal (TS) }\end{array}$ & & & $\begin{array}{c}\bullet \text { FX-460 } \\
\text { BREATHABLE } \\
\text { MASONRY }\end{array}$ & & & & \\
\hline & & & & $\begin{array}{l}\text { COATING } \\
\text { SYSTEM }\end{array}$ & & & & \\
\hline
\end{tabular}

It should be mentioned that the service life of zinc-rich primer-based coating systems has been reported to last as much as 30 years (Kline 2012). A specification guide for the application of coating system with zinc-rich primers for steel bridges is available in the literature (Guide Specification for Application of Coating Systems with Zinc-Rich Primers to Steel Bridges 2006). Additionally, analytical methods have been developed to compute reduced loading capacity of bridge sections with deteriorated steel beams (Van de Lindt et al. 2005).

In order to lower the cost of coatings on new steel bridges, reducing the number of the coats required on the beam has been proposed. A recently-published study (Yao et al. 2011) evaluated the performance of eight different one-coat systems and compared it to one three-coat system and one twocoat system. The results showed that although the one-coat 


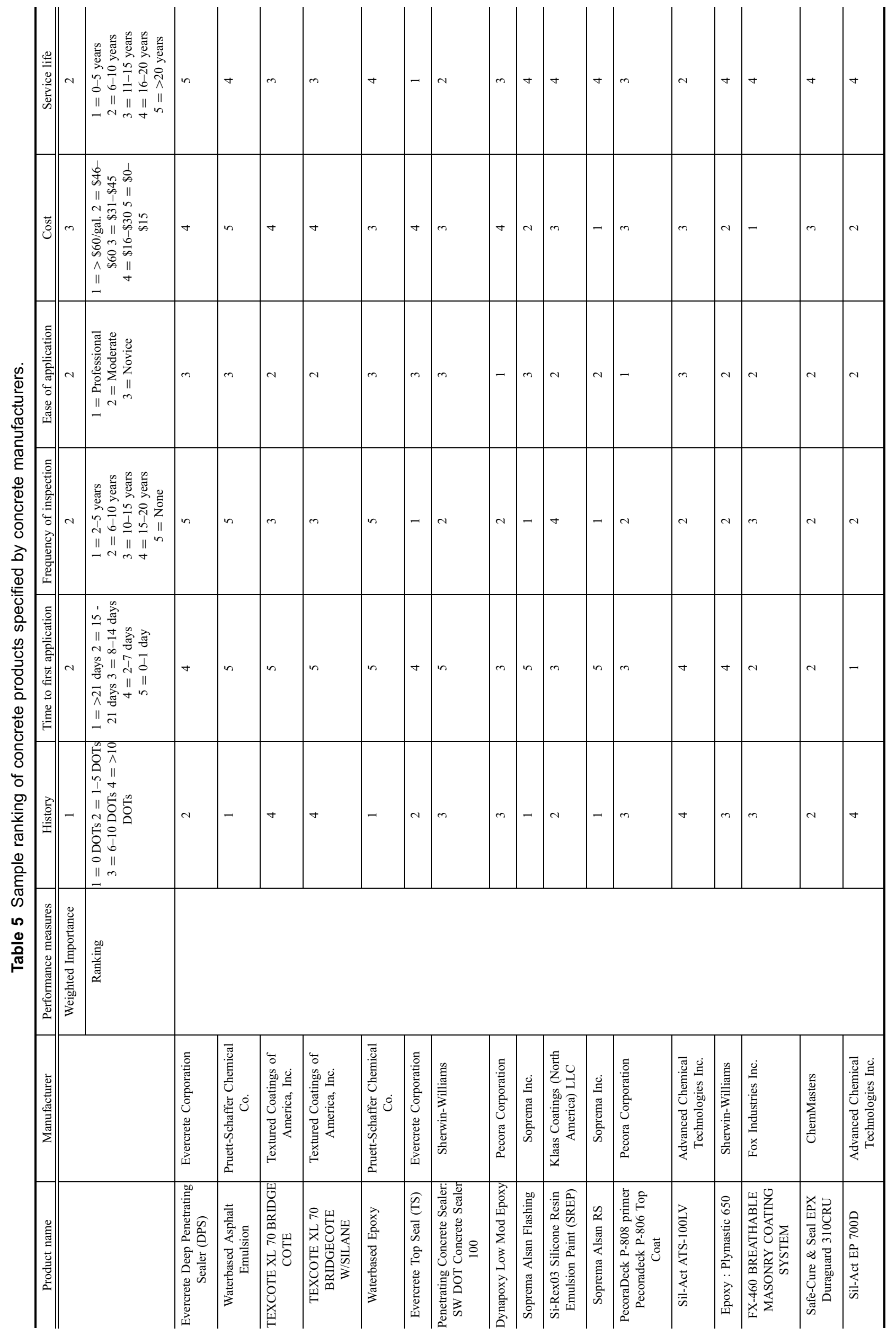




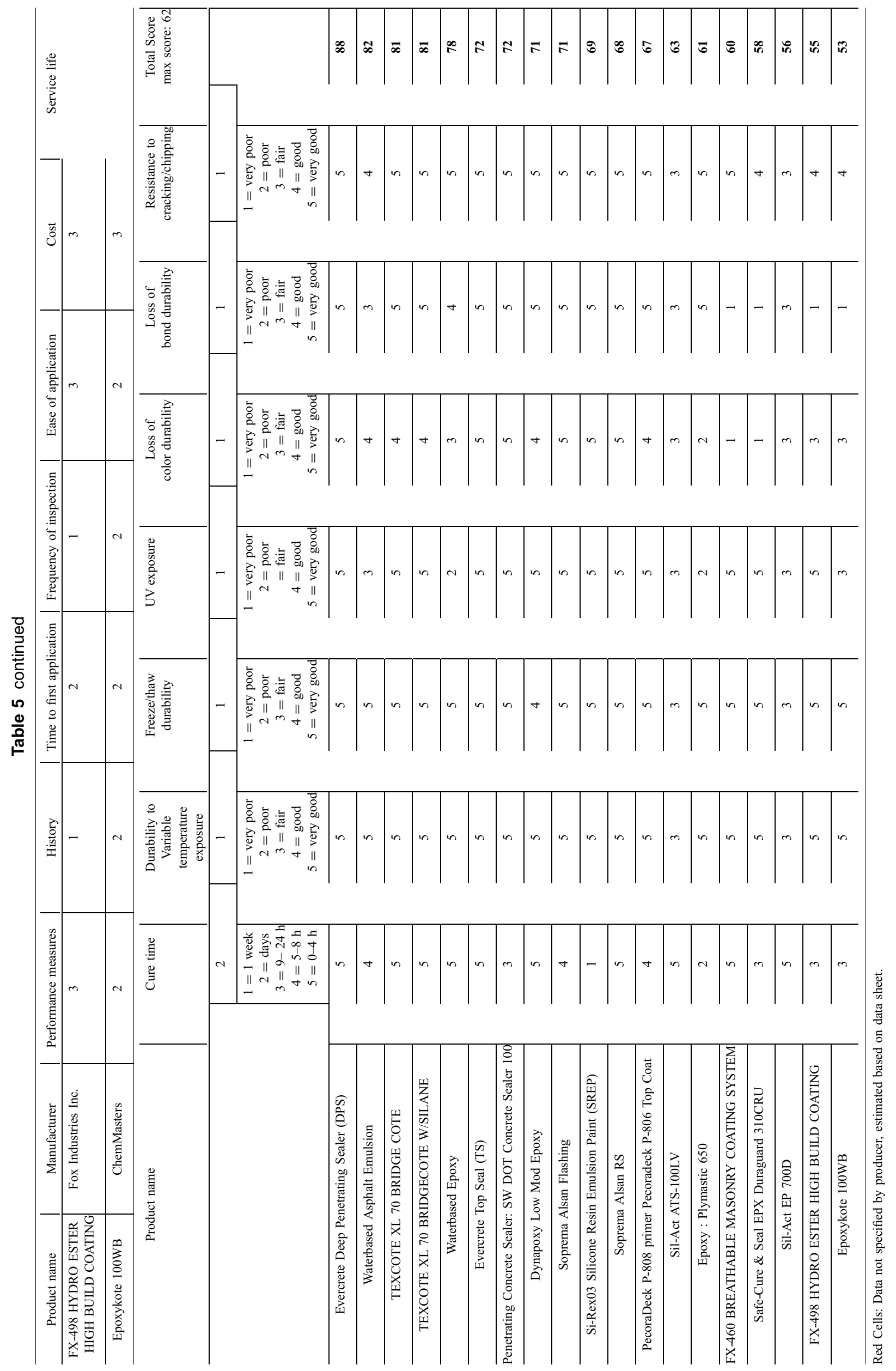




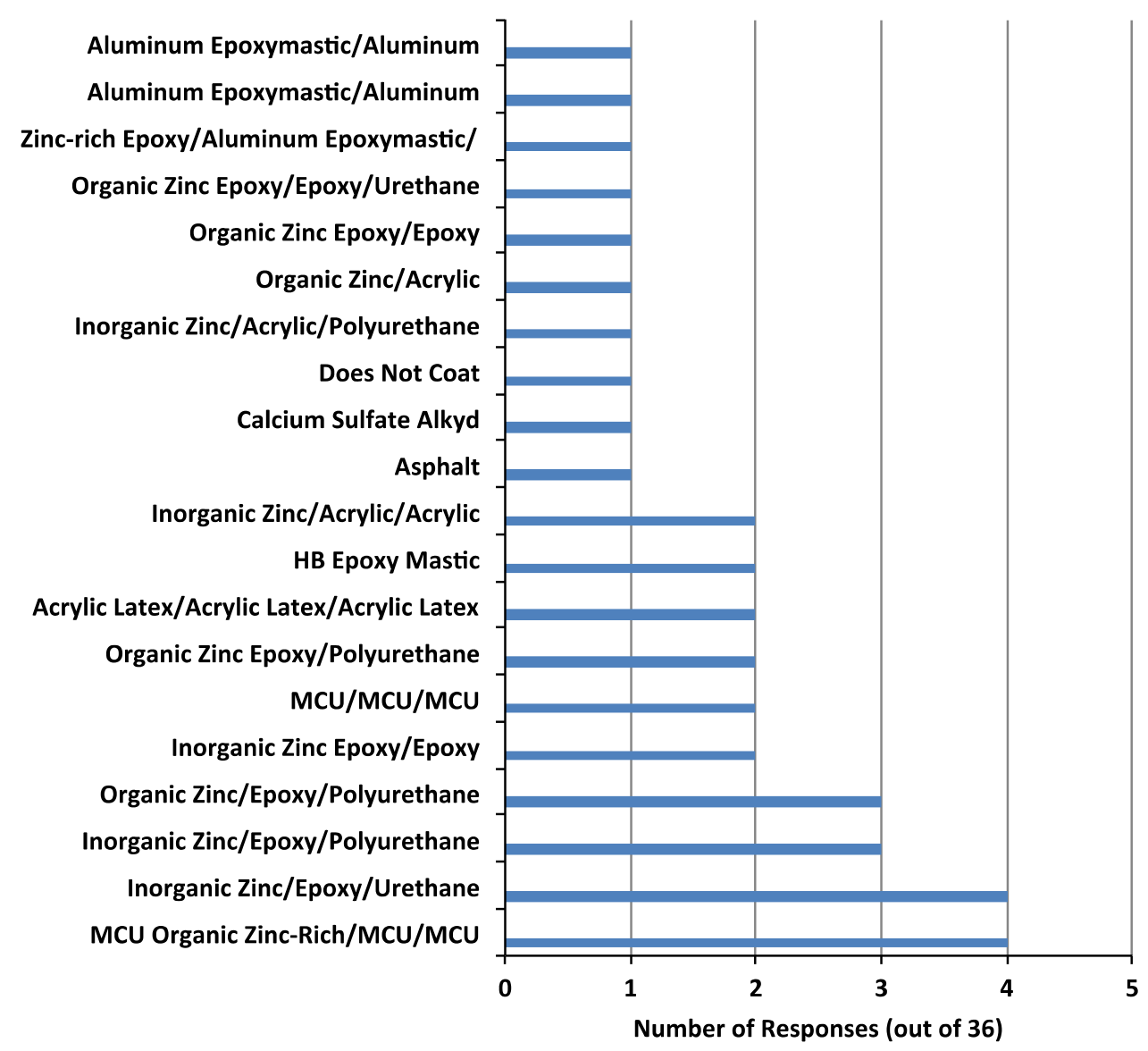

Fig. 3 Coating systems specified in steel coatings survey responses.

systems demonstrated promising performance, they did not perform as well as the three-coat systems under accelerated laboratory and outdoor exposures.

\subsection{Survey Results for Steel Coatings and Treatments}

The summary of survey responses regarding steel coating products has been presented in Fig. 3, while specific products have been listed in Table 6. Among DOTs that replied to the survey, $29 \%$ listed using an inorganic zinc primer with an epoxy mid-coat and urethane top-coat for treating steel beam ends. The other systems listed for new steel were inorganic zinc-rich primer with either one or two layers of acrylic latex on top. In one case, a DOT replied that it does not regularly coat beam ends on its infrastructure components. The coatings used on existing steel varied more than the coatings for new steel; however, $58 \%$ of DOTs reported to be using zinc-rich based systems. Other steel coating systems reported include a zinc-rich epoxy primer with an epoxy mid-coat and a urethane top-coat. Other systems reported that comprised of three layers include: three layers of acrylic latex, an organic zinc primer with an epoxy midcoat and a urethane top-coat, and an aluminum epoxymastic primer with an aluminum epoxymastic mid-coat and an acrylic top-coat. Table 6 summarizes the different products that were reported in the steel coatings survey.
The DOT survey results indicated the most common treatments for new steel were:

- Inorganic Zinc Primer/Epoxy Mid Coat/Polyurethane Top Coat $(21 \%)$.

- Inorganic Zinc Primer/Epoxy Mid Coat/Urethane Top Coat $(16 \%)$.

- Inorganic Zinc Primer/Acrylic Mid Coat/Acrylic Top Coat $(16 \%)$.

- Organic Zinc Primer/Epoxy Mid Coat/Polyurethane Top Coat $(11 \%)$.

Some of the specific products correlate to the systems that were most frequently reported by the DOT's:

- Inorganic Zinc Primer/Epoxy Mid Coat/Polyurethane Top Coat - Carbonzinc 11 HS/Carboguard 893/Carbothane $133 \mathrm{HB}$. This specific set of products was reported by both, Oregon DOT and New Hampshire DOT.

- Organic Zinc Primer/Epoxy Mid Coat/Polyurethane Top Coat - Carbozinc 859/Carboline 888/Carboline 133 HB. This specific set of products was reported by New Hampshire DOT.

The results from the section corresponding to the systems used for existing steel varied significantly. It is worth noting that $78 \%$ of the systems reported by different DOT's for existing steel bridge components were zinc-based primers, including Oregon, Florida, New Hampshire, Alabama, and 
Table 6 Beam end coatings reported by steel manufacturers.

\begin{tabular}{|c|c|c|}
\hline System recommended & Product names & Manufacturers \\
\hline Organic Zinc Rich Moisture Cured Urethane & Wasser MC Zinc & Wasser \\
\hline Moisture Cured Urethane & Ferrox B & Wasser \\
\hline Moisture Cured Urethane & Ferrox A & Wasser \\
\hline Moisture Cured Urethane - Zinc Rich & Corothane I Galvapac & Sherwin Williams \\
\hline Moisture Cured Urethane & Ironox $\mathrm{B}$ & Sherwin Williams \\
\hline Moisture Cured Urethane & Ironox $\mathrm{A}$ & Sherwin Williams \\
\hline Solvent Based Inorganic Zinc & Carbozinc II HS & Carboline \\
\hline Cycloaliphatic Amine Epoxy & Carboline 893 & Carboline \\
\hline Aliphatic Acrylic-Polyester Polyurethane & Carboline $133 \mathrm{HB}$ & Carboline \\
\hline Organic Zinc Rich Epoxy & Carbozinc 859 & Carboline \\
\hline Epoxy Polyamide & Carboline 888 & Carboline \\
\hline Aliphatic Acrylic-Polyester Polyurethane & Caboline $133 \mathrm{HB}$ & Carboline \\
\hline Zinc \& Micaceous Iron oxide Urethane & Wasser MC-Miozinc & Wasser \\
\hline Moisture Cured Urethane & Wasser MC Miomastic & Wasser \\
\hline Moisture Cured Urethane & Wasser MC Miomastic & Wasser \\
\hline Zinc \& Micaceous Iron oxide Urethane & Wasser MC Miozinc & Wasser \\
\hline Moisture Cured Urethane & Wasser MC Tar & Wasser \\
\hline Moisture Cured Urethane & Wasser MC Tar & Wasser \\
\hline Organic Zinc Rich Polyamide Epoxy & Zinc Clad III HS & Sherwin Williams \\
\hline Acylic Polyurethane & Acrolon $218 \mathrm{HS}$ & Sherwin Williams \\
\hline Calcium Sulfonate Alkyd & AS 8301 Series & Watson Coatings Inc. \\
\hline Zinc Rich Epoxy & Interzinc $315 \mathrm{~B}$ & Internation Paints \\
\hline Epoxy & Intergard $475 \mathrm{HS}$ & Internation Paints \\
\hline Inorganic Zinc Rich Ethyl Silicate & InterZinc $22 \mathrm{HS}$ & Internation Paints \\
\hline Epoxy & Intergard $475 \mathrm{HS}$ & Internation Paints \\
\hline Organic Zinc Rich Moisture Cured Urethane & MC Zinc 100 & Wasser \\
\hline Moisture Cured Urethane & MC Miomastic 100 & Wasser \\
\hline Moisture Cured Urethane & MC Ferrox A & Wasser \\
\hline Urethane & MC-Universal Primer DTM & Wasser \\
\hline Moisture Cured Urethane & Ferrox B & Wasser \\
\hline Moisture Cured Urethane & Ferrox A & Wasser \\
\hline High Build Epoxy Mastic & Corlar $2.1 \mathrm{ST}$ & DuPont Industrial Coatings \\
\hline Aliphatic Poluyurethane Enamel & Imron $3.5 \mathrm{HG}$ & DuPont Industrial Coatings \\
\hline High Build Epoxy Mastic & Corlar $2.1 \mathrm{ST}$ & DuPont Industrial Coatings \\
\hline Polyurethane & Imron Industrial Strength & DuPont Industrial Coatings \\
\hline Organic Zinc Rich Epoxy & Zinc Clad III HS & Sherwin Williams \\
\hline
\end{tabular}


Table 6 continued

\begin{tabular}{c|c|c}
\hline \multicolumn{1}{c}{ System recommended } & Product names & Manufacturers \\
\hline Acrylic Polyurethane & Acrolon 218 HS & Sherwin Williams \\
\hline $\begin{array}{c}\text { High Solids Aluminum Filled Polyamine } \\
\text { Epoxy }\end{array}$ & Epoxy Mastic Aluminum II & Sherwin Williams \\
\hline $\begin{array}{c}\text { High Solids Aluminum Filled Polyamine } \\
\text { Epoxy }\end{array}$ & Epoxy Mastic Aluminum II \\
\hline Acrylic Polyurethane & Acrolon 218 HS & Sherwin Williams \\
\hline
\end{tabular}

Iowa DOTs. Coatings used in Illinois and California were not zinc based.

\section{Summary and Conclusions}

Corrosion damage of bridge beam/girder ends is a major common problem and the rehabilitation of beam ends has become of increased interest to transportation agencies. One of the leading contributors to beam end failure is the leakage of water through faulty expansion joints. This leakage causes spalling of the concrete and ultimately leads to corrosion of the steel reinforcement. Joint preservation is an important component in extending the life of beam ends (Ahlborn et al. 2002; Basheer et al. 1997). In addition, beam end protection and treatments can be applied to enhance service life of girders.

This paper synthesized what is currently specified by DOTs across the U.S. for the treatment and coating of concrete and steel beam ends. In addition, it highlighted the main features of various products that are currently available from a number of treatment's manufacturers. The existing data related to concrete beam end coatings and treatments is limited and there is an evident need to conduct a comprehensive laboratory comparison of the existing and newly proposed methods. This need has already been identified by a number of DOTs (Palle and Hopwood 2006). Because concrete is a more complex material than steel, its behavior is more difficult to accurately predict over longer service periods. Additionally, the effectiveness of the coating or treatment will also depend on the concrete mixture quality and the age of the concrete substrate (Ghoddousi et al. 2007).

Results from the literature review and the surveys result indicated that most of the state DOTs do not have beam end maintenance and preservation plans (Ahlborn et al. 2002), and frequently there is a lack of differentiation between the whole beam protection and beam-ends protection. However, for example, MDOT has a procedure for prestressed concrete I beam end repair with latex modified concrete (Michigan Department of Transportation Special Provision for Prestressed Concrete I Beam End Repair With Latex Modified Concrete 2011).

The information gathered in this study about different coatings varied in terms of test methods and approval procedures the coatings under went through, which makes direct comparison not very applicable. However, based on the received information, the most recommended coating system for steel beam end coatings are:

- Inorganic Zinc Primer/Epoxy Mid Coat/Polyurethane Top Coat

- Inorganic Zinc Primer/Epoxy Mid Coat/Urethane Top Coat

- Inorganic Zinc Primer/Acrylic Mid Coat/Acrylic Top Coat

- Organic Zinc Primer/Epoxy Mid Coat/Polyurethane Top Coat

For concrete beam end treatments, the only interviewed DOT that specified a product by name was Iowa DOT, that is using Sikagard 62. As such, a comprehensive laboratory evaluation of concrete coatings would be needed to establish basic material characteristics needed for long-lasting beam end-coating.

The synthesis of practice conducted in this research study indicated that there was significant variability in terms of which products were used by the different DOTs and that there was very little consensus among the DOTs in terms of which concrete or steel bridge beam end treatments are the most promising. The state-of-the-practice revealed that a comprehensive laboratory evaluation, perhaps conducted at the national scale, would greatly assist in effectively selecting the best available beam end treatments and coatings.

\section{Acknowledgments}

The authors gratefully acknowledge the support of the Pennsylvania Department of Transportation through contract No. 100402. The authors specially thank the Project Manager, Mrs. Kristin Langer, and other PennDOT staff for their valuable input throughout the duration of the project.

\section{Open Access}

This article is distributed under the terms of the Creative Commons Attribution License which permits any use, distribution, and reproduction in any medium, provided the original author(s) and the source are credited. 


\section{References}

ACI 345.1R-06 Guide for Maintenance of Concrete Bridge Members. (2006). American Concrete Institute, Farmington Hills, Michigan.

ACI Committee 546 Concrete Repair Guide. (1996). ACI 46R96, American Concrete Institute, Farmington Hills, MI.

Ahlborn, T. M., Kasper, J. M., Aktan, H., Koyuncu, Y., \& Rutyna, J. (2002). Causes and cures of prestressed concrete I-beam end deterioration. Report No. CSD 2002-02, Center for Structural Durability, Michigan Tech Transportation Institute, and Michigan Department of Transportation Report RC-112, Lansing, MI.

Al-Gahtani, A. S., Ibrahim, M., Maslehuddin, M., \& Almusallam, A. A. (1999). Performance of concrete surface treatment systems. Concrete International, 21(1), 64-68.

Basheer, P. A. M., Basheer, L., Cleland, D. J., \& Long, A. E. (1997). Surface treatments for concrete: Assessment methods and reported performance". Construction and Building Materials, 11(7-8), 413-429.

Cady, P. D. (1994). Sealers for portland cement concrete highway facilities. NCHRP Synthesis Report 209, Transportation Research Board, Washington, DC.

Ghoddousi, P., Raiss Ghasemi, A. M., Parhizkar, T. (2007). The effect of concrete quality on performance of surface treatment materials. In: R. N. Kraus, T. R. Naik, P. Claisse, H. Sadeghi-Pouya, ed. Proceedings of the international conference on sustainable construction materials and technologies, 11-13 June 2007 Coventry, Special papers proceedings, Pub. UW Milwaukee CBU, 78-84.

Grand Challenges for Engineering (2012). National Academy of Engineering of the national academies. Accessed on June 7, 2002, from http://www.engineeringchallenges.org.

Guide Specification for Application of Coating Systems with Zinc-Rich Primers to Steel Bridges. (2006). AASHTO/ NSBA Steel Bridge Collaboration, SSPC: The Society for Protective Coatings.

Helsel, J. L., \& Wissmar, K. (2008). Estimating the cost and service life of protective coatings. Journal of Protective Coatings and Linings, 25(7), 32-40.

Henry, G. (2004). Penetrating water-repellent sealers. Concrete International, 26(5), 81-83.

Holland, T. C. (1992). Corrosion protection for reinforced concrete: a summary of corrosion prevention strategies. Concrete Construction, 37(3), 4.

Ibrahim, M., Al-Gahtani, A. S., Maslehuddin, M., \& Dakhil, F. H. (1999). Use of surface treatment materials to improve concrete durability. Journal of Materials in Civil Engineering, 11(36), 36-40.

Kerkhoff, B. (2007). Effects of substances on concrete and guide to protective treatments. Skokie: Portland Cement Association.

Kline E. S. (2012). Bridges for service life beyond 100 years: Corrosion protection for 100 years. Accessed June, 2012, from www.kta.com.

Michigan Department of Transportation Special Provision for Prestressed Concrete I Beam End Repair with Latex Modified Concrete. (2011). 12RC712(A055).
Myers, J., Washer, G., \& Zhang, W. (2010). Structural Steel coatings for corrosion mitigation. Center for transportation infrastructure and safety. Missouri Department of Transportation, Jefferson City, MO.

Needham, D. E. (2000). Prestressed concrete beam end repair. MDOT Report Number R-1380. Federal Highway Administration, Washington, DC.

Palle, S., \& Hopwood, T. (2006). Coatings, sealants and fillers to address bridge concrete deterioration and aestheticsphase I. Kentucky Transportation Center Report No. KTC06-36/SPR291-04-1F.

Paul, J. H. (1998). Extending the life of concrete repairs. Concrete International, 20(3), 62-66.

Portland Cement Association (PCA) Concrete Information. (2001). Effects of Substances on Concrete and Guide to Protective Treatments. IS001, PCA, Skokie, IL.

Silano L. G., (Ed.) (1993). Bridge inspection and rehabilitation. A practical guide. New York, NY: Wiley.

Sohanghpurwala, A. (2006). Manual on service life of corrosion-damaged reinforced concrete bridge superstructure elements. NCHRP Report 558, Transportation Research Board, Washington, DC.

Sohanghpurwala, A. (2009). Protection for life extension of existing reinforced concrete bridge elements. NCHRP Synthesis 398 Report, Transportation Research Board, Washington, D.C.

Status of the Nation's Highways, Bridges, and Transit: Conditions and Performance (2010). Report to Congress, US Department of Transportation, Federal Highway Administration, and Federal Transit Administration.

Tabatabai, H., Ghorbanpoor, A., \& Turnquist-Nass, A. (2005). Rehabilitation techniques for concrete bridges. Wisconsin Highway Research Program, Report Number WHRP 05-01.

Van de Lindt, J. W., \& Ahlborn, T. M. (2005). Development of steel beam end deterioration guidelines. MDOT Research Report RC-1454. Federal Highway Administration, Washington, DC.

Whiting, D. A., Ost, B., Nagi, M., \& Cady, P. D. (1992). Condition evaluation of concrete bridges relative to reinforcement corrosion, vol. 5: Methods for evaluating the effectiveness of penetrating sealers. Publication SHRP-S/ FR-92-107, Strategic Highway Research Program, Washington, DC.

Whiting, D. A., Stejskal, B. G., \& Nagi, M. A. (1993). Conditions of prestressed concrete bridge components: Technology review and field surveys. Publication FHWA-RD93-037, Federal Highway Administration, Washington, DC.

Whiting, D. A., Stejskal, B. G., \& Nagi, M. A. (1998). Rehabilitation of prestressed concrete bridge components by nonelectrical (conventional) methods. Publication FHWA-RD98-189, Federal Highway Administration, Washington, DC.

Williams, J. (2012). Coating of structural steel for public structures, corrosion defense. Federal Highway Administration, Washington, DC. Accessed July 16, 2012, from https://www.corrdefense.org/Academia\%20Government $\%$ 20 and\%20Industry/T-27.pdf. 
Yao, Y., Kodumuri, P., \& Lee, S.-K. (2011). Performance evaluation of one-coat systems for new steel bridges. Publication FHWA-HRT-11-046. Federal Highway Administration, Washington, DC.

Younce, R., Hopwood, T., \& Palle, S. (2008). Experimental concrete coating application on the median barrier of I-65 in Louisville. Kentucky Transportation Center Report No. KTC-08-20/FR155-06-1F. Federal Highway Administration, Washington, DC. 